\title{
Cinética de crescimento de Salmonella Enteritidis envolvida em surtos alimentares no RS: uma comparação com linhagens de outros sorovares
}

Growth kinetics of Salmonella Enteritidis involved in outbreaks of foodborne illness in Rio Grande do Sul, southern Brazil: a comparison with other serovar strains

\author{
Patrícia da Silva MALHEIROS ${ }^{1}$, Cheila Minéia Daniel DE PAULA ${ }^{1}$, Eduardo Cesar TONDO ${ }^{1 *}$
}

\begin{abstract}
Resumo
No período de 1999 a 2002, uma linhagem geneticamente caracterizada de Salmonella Enteritidis esteve envolvida em mais de 90\% das salmoneloses ocorridas no RS. Este trabalho teve por objetivo avaliar a cinética de crescimento dessa linhagem, comparando-a com o crescimento de uma linhagem de $S$. Typhimurium e de $S$. Bredeney não envolvida em surtos alimentares. Para tanto, cada linhagem foi semeada separadamente em caldo nutriente $(\mathrm{CN})$ e em salada de batata com maionese caseira (SMC), os quais foram mantidos a $30{ }^{\circ} \mathrm{C}$ e $9,5^{\circ} \mathrm{C}$. Os resultados obtidos em laboratório foram comparados com os resultados modelados pelo Pathogen Modelling Program, USDA. Em CN, a cinética de crescimento a $30{ }^{\circ} \mathrm{C}$ foi semelhante para todas as linhagens, as quais atingiram aproximadamente 8 log UFC.mL ${ }^{-1}$. Em SMC, a $30{ }^{\circ} \mathrm{C}$, a linhagem de $S$. Enteritidis apresentou maior quantidade de células nas primeiras 6 horas de crescimento, sendo que somente depois de 12 horas todos os microrganismos testados atingiram quantidades semelhantes de células, ou seja, aproximadamente $6 \log \mathrm{UFC} \mathrm{g}^{-1}$. Em CN e em SMC, na temperatura de 9,5 ${ }^{\circ} \mathrm{C}$, não foi detectado crescimento de nenhuma das linhagens testadas de Salmonella durante as primeiras 24 horas, sugerindo que essa temperatura foi suficiente para controlar a multiplicação desses microrganismos. A modelagem bacteriana confirmou a maioria dos resultados obtidos.
\end{abstract}

Palavras-chave: Salmonella; RS; cinética de crescimento; maionese caseira.

\begin{abstract}
From 1999 to 2002, a genetically characterized strain of Salmonella Enteritidis was involved in more than 90\% of foodborne salmonellosis in the state of Rio Grande do Sul, southern Brazil. This work aimed to evaluate the growth kinetics of this strain in comparison with that of other Salmonella serovar strains (S. Typhimurium and S. Bredeney) which were not involved in salmonellosis outbreaks. Each strain was inoculated separately in nutrient broth (NB) and in potato salad prepared with homemade mayonnaise (MS), and incubated at 30 and $9.5^{\circ} \mathrm{C}$. The experimental results were compared with results obtained by the Pathogen Modeling Program, USDA. All the strains showed similar growth characteristics in $\mathrm{NB}$ at $30^{\circ} \mathrm{C}$, reaching approximately $8 \log \mathrm{CFU} \cdot \mathrm{mL}^{-1}$. In MS, the $S$. Enteritidis strain showed higher counts in the first 6 hours when cultivated at $30^{\circ} \mathrm{C}$. Only after 12 hours of incubation did all the microorganisms reach similar counts (approximately 6 log CFU g ${ }^{-1}$ ). No growth of any strain was detected in the first 24 hours in NB and MS at $9.5^{\circ} \mathrm{C}$, suggesting that this temperature was adequate to control the multiplication of the tested Salmonella strains. The bacterial modeling confirmed most of the experimental results.

Keywords: Salmonella; RS; growth kinetics; homemade mayonnaise.
\end{abstract}

\section{Introdução}

Salmonella é responsável por sérios problemas de saúde pública e significativas perdas econômicas, sendo reconhecida como um dos principais agentes de infecção alimentar em diversos países ${ }^{8,12,14,17,21,24}$. No Rio Grande do Sul - RS, Salmonella tem sido reconhecida como o principal microrganismo responsável por Doenças Transmitidas por Alimentos (DTA) na última década $^{3,25}$. Embora diversos sorovares de Salmonella tenham sido encontrados em diferentes alimentos comercializados no RS, o sorovar $S$. Enteritidis tem sido identificado como o causador da maioria das salmoneloses alimentares investigadas pela Secretaria de Saúde do Estado, nos últimos anos ${ }^{6}$. Esse sorovar também tem sido reconhecido como o principal patógeno alimentar, não apenas no RS, mas em outros Estados brasileiros como, por exemplo, Santa Catarina, Paraná e São Paulo ${ }^{1,19,22,26}$, o que demonstra sua importância.

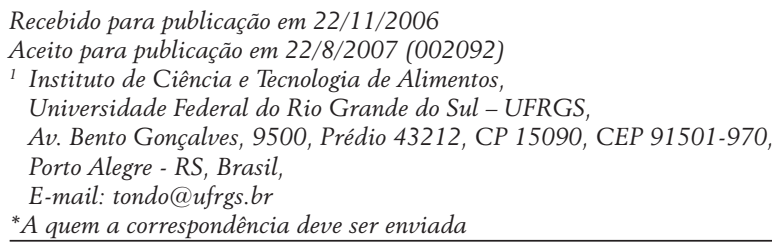

Dentre os alimentos relacionados com as salmoneloses, as preparações à base de ovos têm recebido destaque, sendo a maionese caseira o principal veículo de muitos surtos no RS. Como exemplo disso, COSTALUNGA e $\mathrm{TONDO}^{3}$ analisaram as salmoneloses alimentares ocorridas no Rio Grande do Sul, durante o período de 1997 a 1999, e demonstraram que a maionese caseira foi responsável por $42,45 \%$ das salmoneloses. No período de 2000 a 2001, esse alimento continuou sendo freqüentemente envolvido nas salmoneloses do RS, alcançando $48,1 \%$ dos casos investigados oficialmente pela Secretaria de Saúde deste Estado ${ }^{25}$. A utilização de ovos sem inspeção sanitária, a qual objetiva verificar procedimentos de prevenção e controle de patógenos como Salmonella, em nível de produção, assim como a manipulação inadequada dos alimentos constituíram os principais fatores predisponentes às salmoneloses em $73 \%$ dos surtos investigados no RS, em $2000^{16}$.

Apesar do consumo de maionese caseira não ser recomendado, muitas pessoas optam por consumi-la devido a suas características sensoriais ${ }^{20}$. Uma vez que seu principal ingrediente é o ovo, e esse pode estar contaminado por Salmonella, mesmo sem apresentar características perceptíveis ${ }^{4,10}$, cuidados rigorosos devem ser seguidos na preparação desse alimento. Fato importante a ser ressaltado é que muitas receitas de preparação de maioneses caseiras misturam ovos crus com ovos cozidos, possibilitando 
que um único ovo contaminado provoque a contaminação de todo o produto ${ }^{23}$. Apesar do sorovar $S$. Enteritidis ser freqüentemente relacionado com ovos ${ }^{10}$, ele não é o único sorovar de Salmonella encontrado nesse alimento. O maior envolvimento da $S$. Enteritidis com os casos de salmonelose veiculados pela maionese caseira pode estar relacionado não somente com sua prevalência em ovos, mas também com características que permitam maior eficiência de crescimento que demais sorovares.

O objetivo deste trabalho foi avaliar a cinética de crescimento, em meio de cultura e em salada de batata com maionese caseira mantidos a 30 e $9,5{ }^{\circ} \mathrm{C}$, de uma linhagem de Salmonella Enteritidis envolvida em diversas salmoneloses ocorridas no RS. Os resultados obtidos foram comparados com a cinética de crescimento de linhagens de outros sorovares de Salmonella, os quais não foram envolvidos em surtos alimentares. Além disso, também objetivou-se comparar os resultados experimentais com dados obtidos por modelagem bacteriana executada no programa Pathogen Modelling Program (USDA).

\section{Materiais e métodos}

\subsection{Linhagens bacterianas}

Foram utilizadas linhagens de Salmonella enterica de três sorovares distintos. Um dos sorovares foi $S$. Enteritidis (linhagem SE86) isolado de repolho, em um surto de salmonelose ocorrido no Rio Grande do Sul, em 1999. Esse microrganismo foi caracterizado por métodos fenotípicos e genotípicos por GEIMBA $^{7}$ e apresentou o mesmo perfil genotípico das linhagens de $S$. Enteritidis envolvidas na maioria dos surtos de salmonelose ocorridos no período de 1999 a 2002, no Rio Grande do Sul ${ }^{6,18}$. A SE86 foi gentilmente cedida pela Prof. Dra. Mercedes Passos Geimba do Instituto de Biociências, da Pontifícia Universidade Católica do Rio Grande do Sul (PUC/RS). As duas outras linhagens estudadas nesse trabalho foram de $S$. Typhimurium e S. Bredeney isoladas, em 1999, a partir de fezes de aves e de um embutido, respectivamente. Esses sorovares foram escolhidos, uma vez que os registros da Vigilância Sanitária do RS demonstram pouco ou nenhum envolvimento dos mesmos com os casos de salmoneloses neste Estado, nos últimos anos. Ambos os microrganismos foram gentilmente cedidos pela Prof Dra. Marisa de Itapema Cardoso, do Laboratório de Medicina Veterinária Preventiva da Faculdade de Veterinária da Universidade Federal do Rio Grande do Sul - UFRGS.

\subsection{Preparação do pré-inóculo e inóculo}

Para obtenção do pré-inóculo, uma colônia isolada de cada sorovar foi semeada, separadamente, em Caldo Brain Heart Infusion (BHI; Biobrás) mantido a $37{ }^{\circ} \mathrm{C}$ por 24 horas. Em seguida, $20 \mu \mathrm{L}$ de cada cultura, separadamente, foram semeados em Caldo Nutriente (CN; Synth) e então incubados a $37{ }^{\circ} \mathrm{C}$ por 24 horas, para obtenção da cultura bacteriana fisiologicamente ativada.

\subsection{Curva de crescimento em meio de cultura}

A cultura de cada sorovar de Salmonella foi submetida a diluições decimais seriadas em água peptonada 0,1\% (Vetec), resultando em um inóculo de aproximadamente $10^{2}$ UFC.
$\mathrm{mL}^{-1}$ de Caldo Nutriente. $\mathrm{O} \mathrm{CN}$ inoculado foi mantido em duas temperaturas distintas, 30 e $9,5^{\circ} \mathrm{C}$. A quantidade de unidades formadoras de colônias (UFC) de Salmonella foi quantificada pela técnica de gotas, segundo MILES e MISRA ${ }^{15}$. Nessa técnica, $20 \mu \mathrm{L}$ das diluições a serem quantificadas foram colocados sobre a superfície de Ágar Nutriente, e então deixados para secar em temperatura ambiente, dentro de uma câmara de fluxo laminar (Labenco), previamente esterilizada. Em seguida, as placas foram tampadas e incubadas a $37^{\circ} \mathrm{C}$ por 18 horas, e as colônias bacterianas quantificadas e expressas em UFC.mL $\mathrm{mL}^{-1}$. O experimento foi realizado em duplicata e o limite de detecção do método de contagem foi, no mínimo, de 25 UFC.mL $\mathrm{mL}^{-1}$.

\subsection{Curva de crescimento em salada de batata com maionese caseira (SMC)}

Os ovos utilizados para a produção da maionese foram provenientes de um aviário onde foram testadas 100 aves para a presença de Salmonella, através de swab cloacal. Cada swab foi transferido para $10 \mathrm{~mL}$ de água peptonada $0,1 \%$ estéril, transportados sob refrigeração até o Instituto de Ciência e Tecnologia de Alimentos - UFRGS e então testados para a presença de Salmonella pelo método descrito por $\mathrm{FDA}^{5}$. As aves foram testadas em um único momento e todas as amostras coletadas apresentaram ausência de Salmonella. Somente ovos sem rachaduras e contaminação fecal visível foram selecionados para os experimentos. No laboratório, os ovos foram imersos em álcool 70\%, por 30 minutos, para descontaminação superficial. Logo após a imersão, foram quebrados assepticamente, e as gemas colocadas em frasco estéril para preparação da emulsão ${ }^{4}$.

Para a preparação da maionese caseira, uma gema cozida foi misturada a uma gema crua e, então, adicionados $60 \mathrm{~mL}$ de óleo de soja até formar a emulsão. Nessa emulsão foram inoculadas aproximadamente $10^{3}$ UFC. $\mathrm{mL}^{-1}$ de cada sorovar de Salmonella, separadamente. Para a confirmação desse número de bactérias inoculadas em cada emulsão, o inóculo foi diluído em água peptonada $0,1 \%$ e quantificado pela técnica de MILES e MISRA ${ }^{15}$. Logo em seguida, cada emulsão foi adicionada a 200 gramas de batatas cozidas já resfriadas, a fim de atingir aproximadamente contagens iniciais de até $10 \mathrm{UFC} . \mathrm{g}^{-1}$ de Salmonella em SMC. As SMC foram incubadas em estufa a $30{ }^{\circ} \mathrm{C}$ ou em geladeira regulada para $9,5^{\circ} \mathrm{C}$. Para o isolamento e quantificação de Salmonella, após cada um dos tempos de incubação, foram coletadas 10 gramas de SMC, as quais foram diluídas decimalmente em água peptonada 0,1\%. Em seguida, $20 \mu \mathrm{L}$ das diluições foram semeados em duplicata, em Ágar Nutriente (Merck) e em Ágar Seletivo XLD (Acumedia). As placas foram incubadas a $37^{\circ} \mathrm{C}$ por 24 horas, sendo em seguida, as colônias típicas de Salmonella, quantificadas pela técnica de gotas. O experimento foi realizado em duplicata.

\subsection{Modelagem bacteriana e comparação das curvas de crescimento}

As curvas de crescimento em CN e em SMC foram comparadas com curvas de crescimento realizadas por modelagem bacteriana obtidas pelo Pathogen Modelling Program, do United States Department of Agriculture (USDA), versão 6.1. 
O tempo médio de geração experimental foi calculado na fase exponencial de crescimento e comparado com a modelagem bacteriana. A velocidade específica de crescimento foi calculada apenas com base nos dados experimentais, uma vez que o programa não calcula essa variável. As equações para o cálculo das variáveis citadas estão abaixo descritas ${ }^{13}$.

Tempo médio de geração $(G)$ :

$\mathrm{G}=\frac{\mathrm{t}}{3,322\left(\log \mathrm{N}_{\mathrm{f}}-\log \mathrm{N}_{\mathrm{i}}\right)}$

onde: $\mathrm{t}=$ tempo transcorrido (em minutos)

$\mathrm{N}_{\mathrm{i}}=$ número inicial de células (em UFC. $\mathrm{mL}^{-1}$ )

$\mathrm{N}_{\mathrm{f}}=$ número final de células (em UFC.mL ${ }^{-1}$ )

Velocidade específica de crescimento $(\mu)$ :

$\mu=\frac{1 \mathrm{nN}_{\mathrm{f}}-1 \mathrm{nN} \mathrm{N}_{\mathrm{i}}}{\mathrm{t}}$

onde: $\mathrm{t}=$ tempo transcorrido (em minutos)

$\mathrm{N}_{\mathrm{i}}=$ número inicial de células (em UFC. $\mathrm{mL}^{-1}$ )

$\mathrm{N}_{\mathrm{f}}=$ número final de células (em UFC.mL ${ }^{-1}$ )

\subsection{Análise estatística}

As diferenças de crescimento foram analisadas com assistência do Núcleo de Estatística da UFRGS, utilizando o software SPSS versão 13.

\section{Resultados e discussão}

A cinética de crescimento em $\mathrm{CN}$ incubado a $30{ }^{\circ} \mathrm{C}$ foi bastante semelhante para as três linhagens testadas. Como demonstrado na Figura 1, todas as linhagens permaneceram aproximadamente duas horas em fase lag, mesmo sendo provenientes de inóculos realizados em $\mathrm{CN}$. A partir desse período, as linhagens avaliadas atingiram a fase exponencial de crescimento, a qual

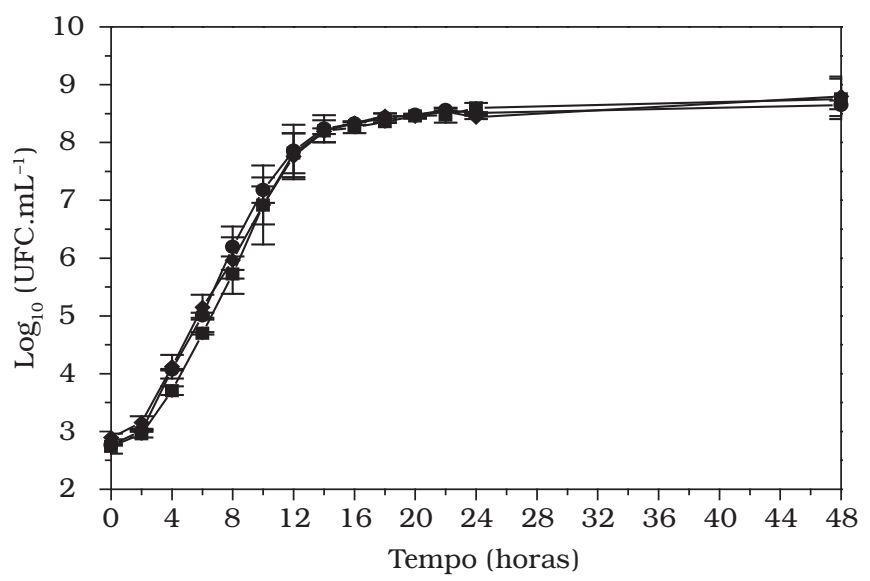

Figura 1. Curva de crescimento, em Caldo Nutriente, na temperatura de $30^{\circ} \mathrm{C}$. Salmonella Enteritidis SE86 ( ), Salmonella Typhimurium (•), Salmonella Bredeney $(\bullet)$. Cada ponto está representado pelo desviopadrão $(\mathrm{n}=4)$. durou aproximadamente 12 horas, demonstrando tempo médio de geração e velocidade específica de crescimento semelhantes, ou seja, as linhagens avaliadas de $S$. Typhimurium e $S$. Bredeney apresentaram tempo médio de geração $(G)$ de 0,69 horas e velocidade específica de crescimento $(\mu)$ de $0,44 \mathrm{log} / \mathrm{h}$, enquanto que a S. Enteritidis SE86 apresentou $G=0,71$ horas e $\mu=0,42 \mathrm{log} / \mathrm{h}$. Todos os microrganismos testados atingiram a fase estacionária após 14 horas de cultivo, sendo que esta apresentou duração de pelo menos 48 horas. Os parâmetros de crescimento encontrados nestes experimentos foram comparados com o crescimento de Salmonella spp. modelado pelo programa Pathogen Modelling Program (USDA). Embora esse programa não especifique o tipo de meio de cultura utilizado para a simulação de crescimento desse microrganismo, o tempo de geração modelado ficou entre 0,4 e 0,6 horas, ou seja, menores do que os tempos médios de geração das linhagens testadas neste estudo, principalmente em relação a $S$. Enteritidis SE86. Segundo a modelagem realizada, a duração média da fase lag foi de 3,1 horas e a população microbiana atingiu a fase estacionária (aproximadamente $10^{8}$ UFC. $\mathrm{mL}^{-1}$ ) após 15 horas de cultivo.

Segundo HUMPHREY ${ }^{11}$, a dose infectante de Salmonella para humanos saudáveis varia entre $10^{6}$ e $10^{8}$ UFC, embora tenham sido relatadas salmoneloses alimentares com doses muito menores. De acordo com o programa de modelagem, uma cultura de Salmonella de aproximadamente $2 \log$ UFC. $\mathrm{mL}^{-1}$ atingiria a dose infectante de $10^{6}$ UFC.mL ${ }^{-1}$ entre 7,1 e 13,5 horas. Neste estudo, a linhagem testada de $S$. typhimurim atingiu essa dose em aproximadamente 9 horas, enquanto a S. Enteritidis SE86 e a linhagem de $S$. Bredeney, em aproximadamente 8 horas.

Os experimentos conduzidos a $9,5{ }^{\circ} \mathrm{C}$ em CN, demonstraram que as linhagens analisadas permaneceram em fase lag pelo menos por 48 horas, sendo que neste período as cepas de $S$. Bredeney e $S$. Typhimurium apresentaram cerca de $0,5 \log$ UFC.mL ${ }^{-1}$ a mais que as de S. Enteritidis SE86 (Figura 2). Uma explicação para tanto pode ser atribuída ao fato de que células microbianas expostas a temperaturas reduzidas geralmente apresentam aumento de suas fases lag

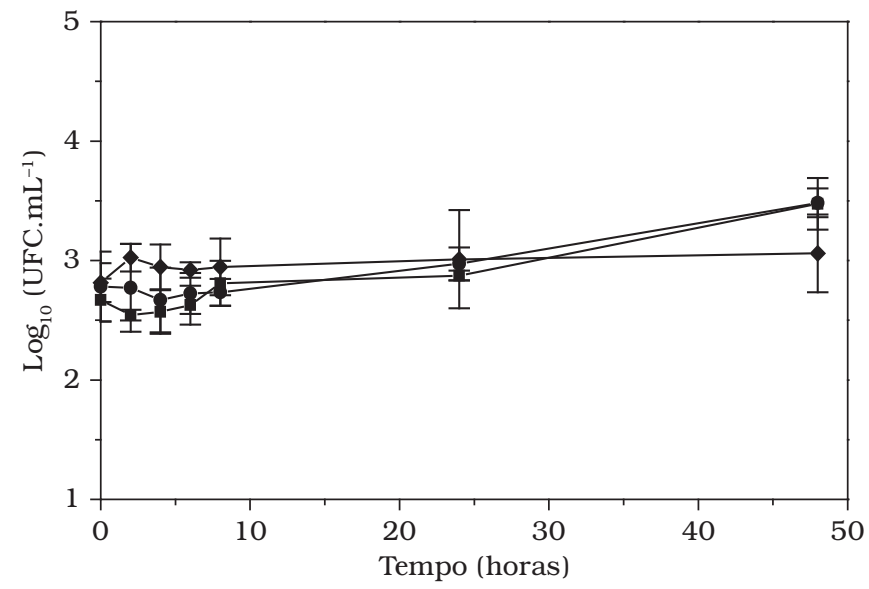

Figura 2. Curva de crescimento, em Caldo Nutriente, na temperatura de $9,5^{\circ} \mathrm{C}$. Salmonella Enteritidis SE86 ( $\bullet$ ), Salmonella Typhimurium (•), Salmonella Bredeney $(\bullet)$. Cada ponto está representado pelo desviopadrão $(\mathrm{n}=4)$. 
devido ao metabolismo reduzido ou injúrias provocadas pelas baixas temperaturas, necessitando tempo maior para sua recuperação.

Com base nos parâmetros de crescimento modelados pelo Pathogen Modelling Program, a fase lag, a $10{ }^{\circ} \mathrm{C}$, teria duração de 37,2 a 90,8 horas (média de 58,1 horas), estando de acordo com os resultados obtidos para os microrganismos testados. O programa apresentou tempo de geração variando de 8,8 a 11,2 horas, sendo que o tempo necessário para atingir $10^{6}$ UFC.mL ${ }^{-1}$ foi de 175 a 239,8 horas.

Neste trabalho, as saladas de batata com maionese caseira (SMC) contaminadas com aproximadamente 1 log UFC.g ${ }^{-1}$ de $S$. Typhimurium, S. Bredeney e S. Enteritidis, separadamente, foram mantidas a $30{ }^{\circ} \mathrm{C}$, por 24 horas, e os resultados das cinéticas de crescimento estão demonstrados na Figura 3. Nesse alimento, observou-se que as linhagens testadas permaneceram aproximadamente 2 horas em fase lag, assim como em CN (Figura 1). A partir desse período, os microrganismos avaliados atingiram a fase exponencial de crescimento, a qual durou aproximadamente 16 horas. O tempo médio de geração e a velocidade específica de crescimento foram semelhantes para os três microrganismos testados, ou seja, a linhagem de $S$. Typhimurium apresentou $\mathrm{G}=0,64$ horas e $\mu=0,47 \mathrm{log} / \mathrm{h}$, a de $\mathrm{S}$. Enteritidis SE86 demonstrou $\mathrm{G}=0,68$ horas e $\mu=0,44 \log / \mathrm{h}$, enquanto que a linhagem de $S$. Bredeney demonstrou $\mathrm{G}=0,66$ horas e $\mu=0,46 \mathrm{log} / \mathrm{h}$. Com base nos experimentos apresentados neste trabalho, os tempos médios de geração em SMC e em CN foram semelhantes. A maior inclinação da reta do $\mathrm{CN}$, demonstrada na Figura 1, pode ser justificada pelo maior número inicial de células.

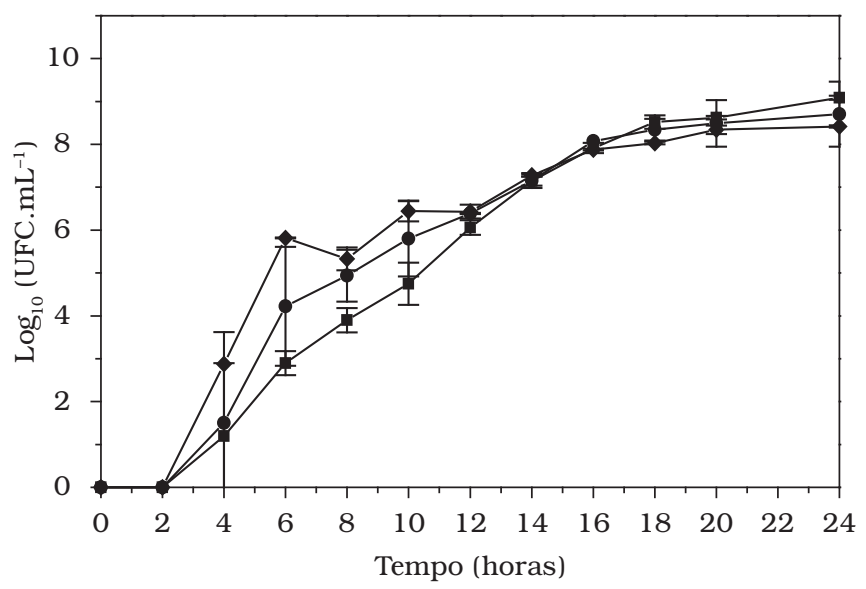

Figura 3. Curva de crescimento, em salada de batata com maionese caseira, na temperatura de $30{ }^{\circ} \mathrm{C}$. Salmonella Enteritidis SE86 ( $)$, Salmonella Typhimurium (•), Salmonella Bredeney $(\bullet)$. Cada ponto está representado pelo desvio-padrão $(\mathrm{n}=4)$.

Apesar das linhagens avaliadas atingirem aproximadamente $10^{8}$ UFC.g ${ }^{-1}$ de SMC praticamente ao mesmo tempo ( 18 horas), em 6 horas de cultivo, a S. Enteritidis SE86 apresentou uma população de 5,84 log UFC.g ${ }^{-1}$, enquanto as linhagens de $S$. Bredeney e de $S$. Typhimurium apresentaram populações de 4,22 log UFC.g ${ }^{-1}$ e 2,90 log UFC.g ${ }^{-1}$, respectiva- mente. As velocidades específicas de crescimento, nesse período, foram: $\mu=2,91 \mathrm{log} / \mathrm{h}$ para $S$. Enteritidis SE86, $\mu=2,11$ $\log / \mathrm{h}$ para a linhagem de S. Bredeney e $\mu=1,44 \log / \mathrm{h}$ para a linhagem de $S$. Typhimurium. O freqüente isolamento da $S$. Enteritidis a partir de ovos ou produtos avícolas ${ }^{9}$ e a capacidade de multiplicação mais rápida da $S$. Enteritidis SE86 nas primeiras horas de cultivo, em SMC, podem justificar o maior envolvimento desse microrganismo com os surtos do $\mathrm{RS}$, envolvendo maionese caseira.

Embora o Pathogen Modelling Program não apresente parâmetros específicos para simulação de crescimento de Salmonella em SMC, nesse programa foram inseridos valores de $\mathrm{pH}(6,7)$ e nível inicial de células (aproximadamente 1 log UFC. $\mathrm{g}^{-1}$ ) semelhantes aos encontrados na SMC. O tempo de geração modelado para Salmonella foi menor do que aqueles encontrados para as linhagens testadas neste experimento, pois a modelagem demonstrou tempo de geração de 0,3 a 0,5 horas, enquanto os experimentos demonstraram tempos de geração de aproximadamente 0,66 horas. Segundo a modelagem bacteriana, o tempo necessário para uma população de 1 log UFC.g ${ }^{-1}$ de Salmonella atingir uma dose infectante de $10^{6} \mathrm{UFC}$ a $30^{\circ} \mathrm{C}$, foi de 8,8 a 17,2 horas, enquanto que experimentalmente as linhagens de Salmonella testadas atingiram essa população em aproximadamente 10 a 12 horas.

Na temperatura de $9,5{ }^{\circ} \mathrm{C}$ em SMC, não foi detectado crescimento das Salmonellas avaliadas durante as 24 horas testadas. Resultados semelhantes foram demonstrados pelo programa de modelagem. Os resultados obtidos experimentalmente não foram demonstrados graficamente, uma vez que as quantidades de UFC. $\mathrm{g}^{-1}$ permaneceram abaixo do nível de detecção da técnica. Embora a RDC 216/2004 da ANVISA ${ }^{2}$ determine que alimentos refrigerados, tais como a maionese caseira, devam ser conservados em temperaturas inferiores a $5{ }^{\circ} \mathrm{C}$, os resultados deste trabalho demonstraram que $9,5{ }^{\circ} \mathrm{C}$ foi suficiente para o controle do crescimento de linhagens dos diferentes sorovares testados de Salmonella. Essa temperatura, ao contrário daquelas preconizadas pela ANVISA, pode ser mais facilmente atingida em serviços de alimentação.

\section{Conclusões}

A cinética de crescimento em $\mathrm{CN}$ foi semelhante para as linhagens avaliadas de S. Typhimurium, S. Enteritidis SE86 e $S$. Bredeney em ambas as temperaturas testadas, 30 e $9,5^{\circ} \mathrm{C}$. A $\mathrm{SMC}$, a $30^{\circ} \mathrm{C}$, possibilitou o rápido crescimento das diferentes linhagens de Salmonella testadas, sendo que $S$. Enteritidis SE86 desenvolveu-se com maior eficiência nas primeiras 6 horas. Esse fato pode estar relacionado com o maior envolvimento desse microrganismo com as salmoneloses do RS, envolvendo maionese caseira. A temperatura de $9,5^{\circ} \mathrm{C}$ demonstrou ser adequada para conter a multiplicação das linhagens de Salmonella testadas e a modelagem bacteriana confirmou a maioria dos resultados obtidos experimentalmente.

\section{Agradecimentos}

Às professoras Dr ${ }^{\text {as }}$. Mercedes Passos Geimba (PUC/RS) e Marisa Ribeiro de Itapema Cardoso (UFRGS) por concederem 
as linhagens bacterianas utilizadas nesse estudo. Ao núcleo de assistência estatística da UFRGS. À CAPES, pelo apoio financeiro, à Divisão de Vigilância Sanitária do RS e ao Laboratório Central (LACEN/RS) pela colaboração.

\section{Referências bibliográficas}

1. ALCOCER. I. et al. Discrimination of Salmonella serovars isolated from chicken meat by REP and ERIC-PCR and phagotyping of Enteriditis sorovar. Ciência e Tecnologia de Alimentos, v. 26, n. 2, p. 1-16, 2006.

2. BRASIL. Resolução-RDC n. 216, de 15 de setembro de 2004 da Agência Nacional de Vigilância sanitária (ANVIA). Dispõe sobre Regulamento Técnico de Boas Práticas para Serviços de Alimentação. Diário Oficial da União, DF, 16 set. 2004.

3. COSTALUNGA, S.; TONDO, E. C. Salmonellosis in Rio Grande do Sul, 1997 to 1999. Brazilian journal of Microbiology, v. 33, n. 4, p. 342-346, 2002.

4. DE PAUlA, C. M. D.; MARIOT, R. F.; TONDO, E. C. Thermal inactivation of Salmonella Enteritidis by boiling and frying egg methods. Journal of Food Safety, v. 25, p. 43-57, 2005.

5. Food and drug administration (FDA). Bacteriological Analyses Manual, $7^{\text {a }}$ Edição, p. 51-69, AOAC, Internation, Arlington, 1992.

6. GEIMBA, M. P. et al. Serological characterization and prevalence of spvR genes in Salmonella isolated from foods involved in outbreaks in Brazil. Journal of Food Protection, v. 67, n. 6 , p. 1229-1233, 2004.

7. GEIMBA. M. P, 2005. Caracterização fenotípica e genotípica de linhagens de Salmonella spp. envolvidas em surtos alimentares ocorridos no Rio Grande do Sul nos anos de 1999 a 2000. Porto Alegre, 2005, 106 p. Tese (Doutorado em Ciências Veterinárias), Faculdade de Veterinária, Universidade Federal do Rio Grande do Sul - UFRGS.

8. GLÓSNICKA, R.; KUNIKOWSKA, D. The epidemiological situation of Salmonella Enteritidis in Poland. International Journal of Food Microbiology, v. 21, n. 1-2, p. 19-30, 1994.

9. HUMPHREY, T. J. et al. The survival of salmonella in shell eggs cooked under simulated domestic conditions. Epidemiology and Infection, v. 103, n. 1, p. 35-45, 1989.

10. HUMPHREY, T. J. Contamination of egg shell and contents with Salmonella Enteritidis: A Review. International Journal of Food Microbiology, v. 21, n. 1-2, p. 31-40, 1994.

11. HUMPHREY, T. J. Salmonella, stress responses and food safety. Science and Society, v. 2, n. 6, p. 504-509, 2004.

12. LACONHA I. et al. Genotypic characterization by PFGE of Salmonella enterica serotype Enteritidis phage type 1, 4, 6 and 8 isolated from animal and human sources in three European countries. Veterinary Microbiology, v. 75, n.2, p. 155-165, 2000 .

13. LEMOS, W. P. C.; GeRMANI, J. C.; RECH, S. B. Manual de Laboratório de Tecnologia Bioquímica. $2^{\mathrm{a}}$. edição. Porto Alegre - UFRGS, 1996. 225 p.
14. LOPALCO, P. L. et al. Epidemiologic study and cost analysis of an Salmonella Enteritidis epidemic. Annali di Igiene, v. 12, n. 4, p. 279-285, 2000.

15. MILLES, A. A. L. e MISRA, S. S. The estimation of the bacterial power of the blood. Journal of Hygiene, v. 38, p. 732-749, 1938.

16. NADVORNY, A.; FIGUEIREDO, D. M. S. SCHMIDT V. Ocorrência de Salmonella sp em surtos de doenças transmitidas por alimentos no Rio Grande do Sul em 2000. Acta Scientiae Veterinariae, Brasil, v. 32, n. 1, p. 47-51, 2004.

17. NASTASI. A.; MAMMINA, C. Epidemiology of Salmonella enterica serotype infections in southern Italy during the years 1980-1994. Research in Microbiology, v. 147, n. 5, p. 393-403, 1996.

18. OLIVEIRA, F. A. Caracterização por susceptibilidade a antimicrobianos, PCR-Ribotipificação e RAPD de Salmonella spp. isoladas de alimentos envolvidos em surtos de Salmonelose ocorridos no Rio Grande do Sul, nos anos de 2001 e 2002. Porto Alegre, 2005, 85 p. Dissertação (Mestrado em Microbiologia Agrícola e do Ambiente), Faculdade de Agronomia, Universidade Federal do Rio Grande do Sul (UFRGS).

19. PERESI, J. T. M. et al. Surtos de enfermidades transmitidas por alimentos causados por Salmonella Enteritidis. Revista de Saúde Pública, v. 32, n. 5, 1-13, 1998.

20. ROADFORD, S. A.; BOARD, R. G. Review: fate of pathogens in home-made mayonnaise and related products. Food Microbiology, v. 10, n. 4, p. 269-278, 1993.

21. RODRIGUE, D. C.; TAUXE, R. V. International in Salmonella Enteritidis: A new pandemic? Epidemiology and Infection, v. 105, n. 1, p. 21-27, 1990.

22. SANTOS, S. M.; KUPEK, E. Serial outbreaks of food-borne disease in Blumenau, Brazil, caused by Salmonella Enteritidis. The Brasilian Journal of Infectious Diseases, Salvador, v. 4, n. 6, p. 275-278, 2000.

23. SANTOS, L. R. et al. Salmonella Enteritidis isoladas de amostras clínicas de humanos e de alimentos envolvidos em episódios de toxinfecções alimentares, ocorridas entre 1995 e 1996, no Estado do Rio Grande do Sul. Higiene Alimentar, Brasil, v. 16, p. 93-99, 2002.

24. SCUDERI G. et al. Foodborne outbreak caused by Salmonella in Italy, 1991-1994. Epidemiology and Infection, v. 116 , p. 257-265, 1996.

25. SILVEIRA, J. B.; TONDO, E. C. Salmonellosis outbreaks occured in Rio Grande do Sul, Southern Brazil, during 2000 to 2001. In: INTERNATIONAL SYMPOSIUM SALMONELLA AND SALMONELOSIS. Epidemiology and Public Health. 2006, Saint Malo, France, Sessão 5, Editora: Pierre Colin e Geneviève Clément, p. 521-522.

26. TAVECHIO, A. T. et al. Salmonella serotypes isolated from nonhuman source in São Paulo, Brazil, from 1996 through 2000. Journal of Food Protection, v. 65, n. 6, p. 1041-1044, 2002. 